\title{
Los "pueblos de españoles" en la monarquía hispánica. \\ La ampliación de jurisdicciones hacia el autogobierno (Buenos Aires, siglo XVIII y primeros años del XIX)*
}

\section{The "pueblos de españoles" in the Hispanic Monarchy. The Extending of Jurisdictions Towards the Self-government}

MARIANA CANEDO

\author{
Resumen \\ El artículo aborda la constitución de "pueblos de \\ españoles" como procesos de consolidación o \\ ampliación de jurisdicciones, y los \\ procedimientos empleados para intentar acceder \\ a los privilegios propios de la titulación de villa. \\ Se analizan cuatro casos impulsados por \\ diferentes actores y las modalidades empleadas \\ en Buenos Aires durante el siglo XVIII y \\ primeros años del siglo XIX. El objetivo es \\ valorizar a los "pueblos de españoles" como \\ cuerpos políticos de la monarquía hispánica \\ inscriptos en tramas de relaciones de poder y \\ coyunturas de cambio desde los propios \\ procesos de constitución.
}

\section{Palabras clave}

Pueblos de españoles - Villas - Monarquía Jurisdicciones - Privilegios

\begin{abstract}
The article approaches the constitution of pueblos de españoles as processes of consolidation or extension of jurisdictions, and the procedures to obtain the privileges of the title of villa. Four cases with different actors and modalities in Buenos Aires during XVIII century and first years of XIX century are analyzed. The purpose is to assess the pueblos de españoles as political corpus of the Hispanic monarchy from their own processes of conformation, involved in power relations and conjunctures of change.
\end{abstract}

Key words

Pueblos de españoles - Villas - Monarchy Jurisdictions - Privileges

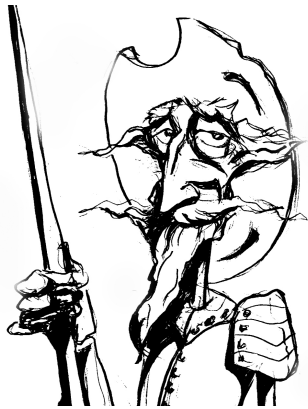

\footnotetext{
Recibido con pedido de publicación el 11 de enero de 2016

Aceptado para su publicación el 20 de marzo de 2016

Versión definitiva recibida el 6 de mayo de 2016
}

Mariana Canedo, Universidad Nacional de Mar del Plata, Consejo Nacional de Investigaciones Científicas y Técnicas, Argentina; e-mail: mcanedo@mdp.edu.ar

\footnotetext{
* Una versión preliminar a este artículo fue presentada en las "IX Jornadas Internacionales de Estudios sobre las Monarquías ibéricas", Tandil, 24 a 26 de setiembre de 2015. Agradezco los comentarios de Marta Bonaudo y los colegas allí presentes, como así también, las sugerencias de los árbitros de la publicación.
} 
Eclipsados por los estudios sobre los pueblos de indios y las villas o ciudades, los "pueblos de españoles" han comenzado a ser analizados en su dimensión política como parte de la monarquía hispánica durante los últimos años. ${ }^{1}$ Pese al progresivo aumento de su presencia durante el siglo XVIII en Hispanoamérica, el peso historiográfico otorgado a las potestades políticas del orden institucional en las comunidades territoriales con autogobierno, debilitó el desenvolvimiento de una mirada análoga hacia otras comunidades. ${ }^{2}$

La denominación "pueblos de españoles", utilizada en las fuentes del siglo XVIII posiblemente para distinguirlos de los pueblos de indios, resulta ambigua al no reflejar la composición heterogénea de su población. ${ }^{3}$ Desde un punto de vista político, los pueblos de españoles estaban incluidos dentro de la monarquía hispánica al igual que los lugares, villas y ciudades pero, en ese mundo ideado en clave corporativa, sus características distintivas fueron

${ }^{1}$ El desplazamiento del paradigma estatista y absolutista iluminó, entre otras cuestiones, las relaciones entre poderes locales y monarquías en diferentes sociedades. GARRIGA, Carlos "Orden jurídico y poder político en el Antiguo Régimen", ISTOR, Revista de Historia Internacional, núm. 16, Año IV, 2004, pp. 1-21; AGÜERO, Alejandro "Ciudad y poder político en el Antiguo Régimen. La tradición castellana". En Cuadernos de Historia, núm. 15, Academia Nacional de Derecho y Ciencias Sociales - Instituto de Historia del Derecho y las Ideas Políticas Roberto I. Peña, Córdoba, 2005, pp. 237-310. Para un panorama sobre los cambios historiográficos influyentes en América inglesa, portuguesa e hispánica, puede consultarse a FRAGOSO, Joao “Modelos explicativos da chamada economía colonial e a ideia da Monarquia Pluricontinental: notas de um ensaio", Història (Sao Paulo), v.31, n.2, 2012, pp.106-145.

2 Sobre el aumento de la población y la multiplicación de pequeños pueblos, véase MORSE, Richard "El desarrollo urbano de la Hispanoamérica colonial". En BETHELL, Leslie (ed.). Historia de América Latina. América Latina colonial: economía, Barcelona, Crítica, 1990, pp.15-48; HÜNEFELDT, Christine "El crecimiento de las ciudades: culturas y sociedades urbanas en el siglo XVIII latinoamericano". En TÁNDETER, Enrique y Jorge LEHUEDÉ (dirs.) Historia general de América Latina. Procesos americanos hacia la redefinición colonial, Madrid: Ediciones UNESCOEditorial Trotta, 2000, pp. 375-406. Un proceso historiográfico similar al de los pueblos de españoles sucedió con comunidades como las "rochelas", los "sitios de libres de todos colores", o los pueblos de afrodescendientes. Ver, entre otros ejemplos posibles, SÁNCHEZ MEJÍA, Hughes “De arrochelados a vecinos: reformismo borbónico e integración política en las gobernaciones de Santa Marta y Cartagena, Nuevo Reino de Granada, 1740-1810", Revista de Indias, vol. LXXV, núm. 264, 2015, pp. 457-488; GARCÍA RUIZ, Luis Juventino Una arena de conflictos. Las corporaciones de Veracruz frente a la preeminencia del poder monárquico, 1754-1810, Tesis doctorado, El Colegio de Michoacán, 2013; MORELLI, Federica "En los confines de la soberanía, Esmeraldas, siglos XVI-XIX", en Claves. Revista de Historia, núm. 1, Montevideo, 2015, pp. 7-31

3 Sobre los diferentes sentidos del término pueblo entre 1780-1850 en el Río de la Plata, véase GOLDMAN, Noemí y DI MEGLIO, Gabriel "Pueblo/Pueblos", en GOLDMAN, Noemí (editora) Lenguaje y revolución. Conceptos políticos claves en el Río de la Plata, 1780-1850, Prometeo, Buenos Aires, 2008, pp.131-143. En el artículo adoptamos la denominación "pueblos de españoles", ante la polisemia de la palabra pueblo, aunque de ahora en más sin comillas. 
expresadas a partir de los privilegios que carecían en comparación con las villas. $^{4}$

En la monarquía hispánica, cabe recordar, predominó la posición del jesuita Francisco Suarez acerca de la atribución de prerrogativas políticas en las comunidades. A diferencia de posturas más amplias que concebían que toda comunidad humana con identidad territorial propia (una aldea, ciudad, comarca o provincia) tenía la capacidad para gobernarse a sí misma y dictar sus propias normas jurídicas, el destacado jurista y teólogo escolástico del siglo XVI distinguió entre comunidades perfectas e imperfectas. ${ }^{5}$ Mientras las perfectas se bastaban a sí mismas, las imperfectas necesitaban del concurso de otros para el desempeño de sus funciones sociales. Las comunidades imperfectas, como los pueblos de españoles, necesitaron para dejar de serlo de un acto de aprobación por parte del rey. ${ }^{6}$

Los pueblos de españoles desde su propio proceso de constitución fueron accediendo a privilegios reales. Sin embargo, no todos lograron la titulación de villa, aunque así lo hubiesen solicitado. Esto sucedió de manera reiterada con los pueblos de españoles que se conformaron en Buenos Aires. ${ }^{7}$ Vinculados a los circuitos comerciales orientados hacia Potosí, Paraguay, Chile o la propia ciudad-puerto, en zonas de la campaña que venían incrementando su población a partir fundamentalmente de migrantes provenientes de zonas aledañas, los pueblos de españoles comenzaron a materializarse hacia mediados del siglo

${ }^{4}$ ROJAS, Beatriz "Repúblicas de españoles: antiguo régimen y privilegios", en Secuencia, núm. 53, mayo-agosto, 2002, pp. 7-47; HESPANHA, Antonio Manuel Direito Luso-Brasileiro no Antiguo Regime, Boiteur, Florianopolis, 2005, pp. 249-279. Sobre la función de los privilegios en sociedades corporativas de antiguo régimen, véase GAYOL, Víctor "Colofón", en ROJAS, Beatriz (coord.) Cuerpo político y pluralidad de derechos. Los privilegios de las corporaciones novohispanas, CIDE-Instituto Mora, 2007, pp. 275-295.

${ }^{5}$ Sobre el poder político como la potestad de decir derecho, estatuir normas y administrar justicia en el grado y sobre el ámbito que le corresponde según su iuristictio, véase GARRIGA, Carlos "Orden jurídico y poder político...", cit.

${ }^{6}$ Una concepción amplia sobre la distribución de prerrogativas en todas las comunidades humanas fue expresada en los escritos del jurista Baldo degli Ubaldi, de Padua, en el siglo XIV. Como señala Hespanha, esta postura se vinculaba con el posicionamiento ante el derecho de las comunas de la península itálica de liberarse de la autoridad del Sacro Imperio Romano Germánico. Francisco Suarez, por su parte, fue coetáneo a las grandes monarquías del antiguo régimen y su posición, como veremos, afianzaba el vínculo súbdito-soberano. HESPANHA, Antonio Manuel Direito Luso-Brasileiro..., cit. pp. 249-279 Sobre Suarez y la teoría de la monarquía barroca, véase HALPERÍN DONGHI, Tulio Tradición política española e ideología revolucionaria de Mayo, Prometeo, Buenos Aires, 2010 [1961], capítulo II.

${ }^{7}$ La jurisdicción de Buenos Aires fue modificando sus alcances jurisdiccionales durante el siglo XVIII, primero como gobernación y luego como intendencia. Los procesos de conformación de pueblos, ciudades y villas fueron diferentes en sus zonas internas. En este trabajo focalizamos la banda occidental de la jurisdicción del cabildo de Buenos Aires -que actualmente suele denominarse campaña de Buenos Aires- por mantener características similares en relación al ecosistema y a las políticas y prácticas de poblamiento durante el periodo abordado. 
XVIII. Estimamos unos treinta pueblos de españoles con diferente estado de consolidación con anterioridad a 1810, a los que se agregarán unos catorce antes de 1860 en un territorio que se extendió hacia el sur y el oeste. ${ }^{8}$ Esta multiplicación de asentamientos, fundamentalmente en las últimas décadas del siglo XVIII y primera del XIX, fue compartida tanto en la zona del litoral rioplatense como en la frontera sur hispanoamericana que comunicaba al complejo portuario rioplatense con la Capitanía General de Chile, pero presentó características propias en las fértiles llanuras de la campaña de Buenos Aires. ${ }^{9}$ Los pueblos de españoles, cercanos y comunicados entre sí, constituyeron un ramillete de pequeñas comunidades imperfectas que formaron parte de la jurisdicción del cabildo de Buenos Aires y los sucesivos gobiernos del siglo XIX. ${ }^{10}$

${ }^{8}$ Miradas de conjunto de los pueblos en Buenos Aires realizadas desde distintas perspectivas, se encuentran en: RAZORI, Amílcar Historia de la ciudad argentina, Imprenta López, Buenos Aires, 1945; DE PAULA, Alberto y GUTIERREZ, Ramón "Las ciudades y el medio rural", en Academia Nacional de la Historia (eds.) Nueva historia de la Nación Argentina, Planeta, Buenos Aires, tomo II, 1999, pp. 47-88; BARRAL, María Elena y FRADKIN, Raúl "Los pueblos y la construcción de las estructuras de poder institucional en la campaña bonaerense (1785-1836)", en Boletín del Instituto de Historia Argentina y Americana "Dr. Emilio Ravignani", núm. 27, 2005, pp. 7-48. Además, contamos con los estudios de caso que, desde enfoques variados, se fueron realizando sobre cada pueblo. Muchos de ellos fueron editados por el Archivo Histórico de la Provincia de Buenos Aires (en adelante AHPBA) desde la década de 1940.

9 Entre los estudios que pueden consultarse para las distintas jurisdicciones de la frontera sur hispanoamericana, se encuentran: URBINA BURGOS, Rodolfo y LORENZO, Santiago La política de poblaciones en Chile durante el siglo XVIII, El Observador, Quillota, 1978; SALAZAR, Gabriel Construcción de Estado en Chile (1800-1837). Democracia de los "pueblos", militarismo ciudadano, golpismo oligárquico, Santiago de Chile, Sudamericana, 2005. PUNTA, Inés Córdoba borbónica. Persistencias coloniales en tiempo de reformas (1750-1800), Córdoba, Universidad Nacional de Córdoba, 2010; RUSTÁN, Elizabeth Las políticas de frontera. Córdoba y Cuyo: 1750-1820, Tesis de Doctorado inédita, Doctorado en Historia, Universidad Nacional de Córdoba, 2013; SUAREZ, Teresa y TORNAY, María Laura "Poblaciones, vecinos y fronteras rioplatenses. Santa Fe a fines del siglo XVIII", en Anuario de Estudios Americanos, tomo LX, n.2, 2003, pp. 521-555; BARRIERA, Darío y FRADKIN, Raúl (coords.) Gobierno, justicias y milicias. La frontera entre Buenos Aires y Santa Fe, 1720-1830, FaHCE, La Plata, 2014; FREGA, Ana Pueblos y soberanía en la revolución artiguista. La región de Santo Domingo Soriano desde fines de la colonia a la ocupación portuguesa, Ediciones de la Banda Oriental, Montevideo, 2007, entre otros. Para un primer ejercicio comparativo en base a las políticas de poblamiento y el acceso a los terrenos puede consultarse, CANEDO, Mariana "Los pueblos de españoles en la jurisdicción de Buenos Aires. Privilegios, oportunidades y conflictos en la conformación y consolidación de la base territorial (17001860)", ponencia presentada en Congreso Latinoamericano de Historia Económica IV, Bogotá, 2014.

${ }^{10}$ La multiplicación de las comunidades imperfectas, junto con otros procesos demográficos, sociales y económicos, influirán en el impulso generado desde Buenos Aires, como en otras ciudades de la región, por abordar el desafío del gobierno de sus campañas. Los estudios sobre las autoridades de los partidos, distritos, parroquias, comandancias, etc. complementan el enfoque de este trabajo. Véase, entre muchos otros, BARRAL, María Elena y FRADKIN, Raúl "Los pueblos y la construcción...", cit.; BARRIERA, Darío y FRADKIN, Raúl (coords.) Gobierno, justicias y milicias., cit. SANJURJO DE DRIOLLET, Inés (coord.) “Justicias inferiores y gobiernos 
En el presente trabajo proponemos avanzar en el conocimiento de los pueblos de españoles, analizando las acciones emprendidas por diferentes actores políticos relacionadas con la propia conformación de estas comunidades imperfectas en la banda occidental de la jurisdicción de Buenos Aires durante el siglo XVIII y primeros años del XIX, y las pretensiones puestas de manifiesto de constituir villas.

Argumentamos que las acciones emprendidas por los actores posicionaron a los pueblos de españoles como cuerpos políticos de la monarquía hispánica desde los propios procesos de conformación. Las tensiones, dilaciones y conflictos generados parecieran haber radicado en que los mismos constituyeron procesos de ampliación o consolidación de jurisdicciones tendientes al autogobierno, inscriptos en tramas de relaciones de poder y coyunturas de cambio.

El enfoque elegido basado en diferentes actores políticos -pobladores, propietarios, autoridades, alcaldes de indios, obispos, cabildos, etc.- que articularon su accionar hacia la conformación de los pueblos, permite incorporar en el análisis las negociaciones, los consensos y conflictos propios de la cultura política de la monarquía hispánica y desplazar los análisis centrados en la lógica unidireccional de las autoridades reales.

El artículo se divide en dos partes. La primera se centra en el análisis de las modalidades de conformación de cuatro pueblos de españoles en Buenos Aires (Villa de San Antonio del Camino, San Pedro, Santiago del Baradero, San Fernando de la Bella Vista), los actores intervinientes y sus respectivos conflictos En la segunda parte se analizan las solicitudes realizadas desde algunos de los pueblos para acceder a la titulación de villas y las limitaciones encontradas. Nuestra intención es lograr un mayor conocimiento sobre los pueblos de españoles como parte de la monarquía hispánica, para justipreciar en futuros trabajos las continuidades y cambios producidos en etapas posteriores.

\section{La formación de pueblos de españoles}

\section{Permiso real para "poblar un pueblo de españoles"}

A través de una compleja trama de lealtades, alianzas, lazos familiares, servicios a la monarquía y pedidos de gracias reales -no carentes de conflictos-, algunos miembros de la elite regional rioplatense fueron ocupando espacios de poder que imbricaban actividades comerciales, productivas, cargos institucionales y comisiones de servicios. El impulso a la construcción de pueblos, consideramos,

en espacios rioplatenses (s.XVIII y primera mitad del XIX)", en Nuevo Mundo Mundos Nuevos [En línea], Debates, Puesto en línea el 10 marzo 2015, consultado el 20 octubre 2015. URL : http://nuevomundo.revues.org/67849 
fue una manifestación más de este tipo de inserción en la comunidad que se puso de manifiesto durante la primera mitad del siglo XVIII. ${ }^{11}$

Francisco de Merlo (1693-1758) fue un vecino de Buenos Aires, oriundo de Navarra, que logró construir un patrimonio económico, social y político relativamente importante en la región. ${ }^{12}$ Estuvo asociado a la conformación del pueblo de San Antonio del Camino, como lo estuvieron Joseph Ruiz de Arellano con el pueblo de San Antonio de Areco, Francisco de Aguiar con San Nicolás de los Arroyos, o Francisco Casco Mendoza con el pueblo de Exaltación de la Cruz. Los cuatro compartieron, entre otras características, el hecho de asignar una porción de terreno para los asentamientos en procesos prácticamente simultáneos, aunque siguiendo caminos diferentes. ${ }^{13} \mathrm{El}$ caso de Merlo se distinguió por solicitar un permiso real para la construcción de un pueblo de españoles, proponer emprenderlo a su costo y recurrir a sus vínculos institucionales-personales para fortalecer la petición que, sin embargo, tuvo una respuesta distante de su inicio.

Con anterioridad, Merlo había formalizado un "acuerdo" con representantes del cabildo eclesiástico -a instancias del gobernador de Buenos Aires- por el establecimiento de la sede parroquial en el oratorio de uso doméstico que había construido en su estancia. ${ }^{14}$ En el documento se afianzaban

${ }^{11}$ CANEDO, Mariana (comp.) Poderes intermedios en la frontera. Buenos Aires, siglos XVIII-XIX. Grupo de Investigación en Historia Rural Rioplatense-Universidad Nacional de Mar del Plata, Mar del Plata, 2013, pp. 23-66. Sobre los procesos sociales y políticos de los vecinos como estimación del grado de inserción en una comunidad, remitimos a HERZOG, Tamar "Ciudad y ciudadanía en el mundo hispano y atlántico", en Anuario IEHS 25 (2010), pp. 167-177.

${ }^{12}$ Merlo se dedicó al comercio interregional hacia los distintos mercados que conducían a Potosí y articuló la producción de ganado mular y vacuno en tierras de la zona norte de la campaña con el mismo fin. También lo ubicamos faenando toros montaraces y vendiendo la corambre a los capitanes de los navíos negreros franceses en las barracas de la Compañía de Guinea, arrendando la recaudación del diezmo de granos del distrito de Luján o recaudando el diezmo de cuatropea de la campaña. En 1716 adquirió en pública subasta y como mejor postor, el cargo de escribano público y de gobierno (perpetuo e irrenunciable). En 1734 fue designado para ocupar el cargo de escribano del cabildo de Buenos Aires, ante la separación de su antecesor del cargo. Actuó como fiador del gobernador Domino Ortiz de Rozas. Fue capitán de milicias, y perteneció a la Tercera Orden de los mercedarios (su hijo fue fraile de la misma orden). BIROCCO, Carlos Cañada de la Cruz. Tierra, producción y vida cotidiana en un partido bonaerense durante la colonia. Municipalidad de Exaltación de la Cruz, Exaltación de la Cruz, 2003, p. 27; CANEDO, Mariana (comp.) Poderes intermedios..., cit., pp. 23-66.

${ }_{13}$ Para profundizar cada caso puede consultarse GARAVAGLIA, Juan Carlos San Antonio de Areco, 1660-1880.Un pueblo de la campaña del Antiguo Régimen a la modernidad argentina, Prohistoria Ediciones, Rosario, 2009; BIROCCO, Carlos Cañada de la Cruz..., cit.; CANEDO, Mariana Propietarios, ocupantes y pobladores. San Nicolás de Los Arroyos, 1600-1860, Universidad Nacional de Mar del Plata, Mar del Plata, 2000, y Poderes intermedios..., cit.

${ }^{14}$ Las menciones sobre la conocida promoción por parte del cabildo eclesiástico, con sede en Buenos Aires, del establecimiento de seis curatos rurales y la designación de las sedes parroquiales suele no explicitar estos mecanismos negociados para el uso de las capillas $u$ oratorios que ya existían. Cabe recordar que el carácter "particular" de un bien de una persona 
los derechos de Merlo sobre el oratorio al especificar las condiciones de uso de la capilla y discriminar el campo de acción del "cura que fuere nombrado en dicho pago y fuere a dicha Capilla" y el del "capellán de Merlo en dicha Capilla". ${ }^{15}$ Específicamente, la capilla constituyó uno de los elementos utilizados para fundamentar la realización del pueblo.

La primera solicitud de Merlo por el pueblo comenzó en 1738 y fue al cabildo de Buenos Aires, dentro de cuya jurisdicción se encontraría el mismo. El permiso, convertido en Real Cédula, llegará en 1755. El cuadro 1 sintetiza la reconstrucción de las peticiones realizadas por Merlo. ${ }^{16}$

o familia aludía a los derechos de posesión, pero sin encontrarse desvinculados -“privados"del conjunto de intereses de la comunidad o república urbana. LEMPÉRIÈRE, Annick "República y publicidad a finales del antiguo régimen (Nueva España)" en GUERRA, François Xavier y LEMPÉRIÈRE, Annick (et al) Los espacios públicos en Iberoamérica. Ambigüedades y problemas. Siglos XVIII-XIX, Fondo de Cultura Económica, México, 2008, pp. 72-79.

15 El acuerdo es reproducido por RODRIGUEZ ARAUZ, Javier Historia de Merlo, Edición del autor, Buenos Aires, 1950, pp. 16-17.

${ }_{16}$ Cada pedido de informe realizado por Merlo tuvo una redacción propia, aunque se focalizara en los mismos argumentos. Los informes se realizaron a los pocos días de ser solicitados. 


\section{CUADRO 1}

\section{Solicitudes de Merlo para la obtención de permiso real para construcción de un pueblo de españoles}

\begin{tabular}{|c|c|c|}
\hline $\mathrm{AÑO}$ & DIRIGIDA a & SOLICITUD \\
\hline 1738 & $\begin{array}{l}\text { Cabildo de Buenos Aires } \\
\text { Gobernador de Buenos } \\
\text { Aires }\end{array}$ & $\begin{array}{l}\text { Se envíe al rey un informe sobre utilidad y conveniencia de } \\
\text { "poblar un pueblo de españoles" }\end{array}$ \\
\hline 1738 & Rey & Permiso para "poblar un pueblo de españoles" \\
\hline 1741 & $\begin{array}{l}\text { Gobernador } \\
\text { Cabildo } \\
\text { Maestre de campo }\end{array}$ & $\begin{array}{l}\text { Se envíe al rey un informe sobre utilidad y conveniencia } \\
\text { de "poblar un pueblo de españoles" }\end{array}$ \\
\hline 1741 & Rey & Permiso para poblar un "pueblo de españoles" \\
\hline 1742 & $\begin{array}{l}\text { Gobernador, } \\
\text { cabildo, } \\
\text { sargento mayor del } \\
\text { presidio de la ciudad. }\end{array}$ & $\begin{array}{l}\text { Se envíe al rey un informe sobre utilidad y conveniencia de } \\
\text { "poblar un pueblo de españoles" }\end{array}$ \\
\hline 1742 & Obispo de Paraguay & $\begin{array}{l}\text { Informe sobre Merlo como buen súbdito de" ambas } \\
\text { Coronas" y apoyo a la propuesta }\end{array}$ \\
\hline 1742 & $\begin{array}{l}\text { Jueces oficiales reales } \\
\text { (tesorero y contador) }\end{array}$ & $\begin{array}{l}\text { Informe al rey de contribución que Merlo había realizado } \\
\text { en } 1739 \text { "en el donativo para el Real Palacio" ( } 150 \text { p. } \\
\text { entregados en plata) y que en } 1741 \text { que había participado } \\
\text { con } 1000 \text { pesos en el "préstamo que se pidió en esta Ciudad } \\
\text { a los Vecinos para la manutención de las Fragatas de } \\
\text { Guerra". }\end{array}$ \\
\hline 1742 & Rey & Permiso para poblar un pueblo de españoles \\
\hline 1753 & Rey & $\begin{array}{l}\text { Exención a los pobladores por tres años de derechos } \\
\text { parroquiales }\end{array}$ \\
\hline 1755 & Gobernador & $\begin{array}{l}\text { Propone nombre Villa de San Antonio del Camino y el } \\
\text { nombre de un juez y un capitán que residen en el pueblo }\end{array}$ \\
\hline 1755 & $\begin{array}{l}\text { Rey al gobernador para } \\
\text { entregar a Merlo }\end{array}$ & Recepción Real Cédula para finalizar pueblo \\
\hline 1755 & Pobladores & $\begin{array}{l}\text { Edicto para publicar domingos en la plaza de la villa } \\
\text { convocando a nuevos pobladores }\end{array}$ \\
\hline 1755 & Gobernador y éste al rey & Propuesta de Seminario de mercedarios en tierras de Merlo \\
\hline
\end{tabular}

Fuente: Elaboración personal a partir de TORRE REVELLO, José Los orígenes y fundación de la Villa de San Antonio del Camino, AHPBA, La Plata, 2004 (reedición digital), “Apéndice documental”.

Si bien la reiteración de las peticiones a las autoridades era una práctica común en el orden jurídico probabilístico de estas sociedades, en el caso de Merlo la insistencia ante la falta de respuesta pareciera evidenciar límites en la modalidad empleada para fortalecer el pedido. ${ }^{17}$ No hemos accedido a documentación que permita reconstruir el recorrido de los pedidos en la península, pero -según se expresaba en el expediente- fue recién en 1744 cuando el fiscal del Consejo de Indias habría tomado vista de la solicitud al rey

${ }^{17}$ Sobre el orden jurídico probabilístico, véase GARRIGA, Carlos “Orden jurídico...", cit. 
y los testimonios que acompañaron el pedido de Merlo. ¿Se extraviaron las solicitudes anteriores? ¿Fueron retenidas en Buenos Aires, o en algún otro lugar de su itinerario, por enfrentamientos entre facciones o personales? ${ }^{18}$ De ser así, algún cambio coyuntural o la amplitud de los testimonios en 1744 -que incluyó a dos obispos y a los jueces oficiales reales- pudo haber generado otro tipo de comunicación con el Consejo.

La propuesta de "poblar un pueblo de españoles" se presentaba como "de utilidad y conveniencia al bien de los caminantes, la construcción del dicho Pueblo por el Bien que considero tendrán en los vecinos, de que se ha de componer". El pueblo sería un asentamiento intermedio entre Buenos Aires y Santa Fe o Córdoba en un contexto de carencia de alternativas "pues apenas los dueños de ellas [estancias y quintas] tienen lo mínimo para sí, y sus familias". ${ }^{19}$ Sin costo para la Corona, Merlo asignaba un terreno y contaba con una capilla funcionando en buen estado. En 1741, ataques indígenas en la zona influyeron en que al proyecto del pueblo se lo considerara como potencial refugio de las familias a las que Merlo proveería de armas, incorporando una función defensiva en la fundamentación.

En los 17 años que transcurrieron durante la gestión de Francisco Merlo para el permiso de construcción del pueblo, se realizaron algunas acciones para ir materializándolo. Ya el padrón de población de la zona de 1744, registró a algunos pocos propietarios de "estancias" o "quintas" o a sus familias "viviendo en el pueblito de Merlo". En 1753, Merlo realizó un padrón para conocer el aumento alcanzado de población a instancias del Consejo de Indias. Al presentarlo consideró a 111 personas, agrupadas en 24 "familias", aclarando que buscaba llegar a las 50. Sin embargo, esta información que se envió al Consejo, contrasta con la lectura nominal que permite diferenciar entre potenciales pobladores y las 8 unidades censadas que efectivamente se encontraban asentadas en los solares (unas 30 personas). ${ }^{20}$

En varias oportunidades se ha señalado la falta de protagonismo de las autoridades reales en los procesos de conformación de pueblos en la jurisdicción de Buenos Aires. ${ }^{21}$ Esta situación resulta aún más notoria si la comparamos con la intensa política de fundación de "villas" realizada hacia

18 MOUTOUKIAS, Zacarias "Las formas complejas de la acción política: justicia corporativa, faccionalismo y redes sociales (Buenos Aires, 1750-1760)", en Jahrbuch für Geschiehte Lateinamerikas, 39, 2002, 69-103.

${ }^{19}$ CANEDO, Mariana Poderes intermedios..., cit., p. 45

${ }^{20}$ Entre la población ya asentada se incluía a la familia del propio Francisco, su hijo cura y otro casado. Los pobladores provenían de Buenos Aires (dos cabezas de unidad censal), y los restantes de Mendoza, Córdoba, Santiago del Estero, Castilla la Vieja, y La Rioja. El asentamiento se manifestaba con un ritmo pausado: en dos casos hacia "más de 10 años", más de 8 (uno), más de 6 años (dos), más de 5 años (dos). CANEDO, Mariana Poderes intermedios..., cit., p. 47

21 DE PAULA, Alberto "Origen, evolución e identidad de los pueblos bonaerenses", Investigaciones y Ensayos, núm.4, 1995, pp. 617-660; BIROCCO, Carlos Cañada de la Cruz...cit. 
mediados de siglo en Chile por algunos gobernadores como José Antonio Manso de Velasco y Domingo Ortiz de Rosas. ${ }^{22}$ En el caso que estamos analizando, más allá del indudable protagonismo de Merlo, la actuación de los gobernadores se expresó en las formas que sintetizamos en el siguiente cuadro.

\section{CUADRO 2}

\section{Actuaciones de los gobernadores de Buenos Aires en torno al establecimiento del pueblo}

\begin{tabular}{|c|c|c|}
\hline GOBERNADOR & ANO & ACCIÓN \\
\hline Bruno Zabala & 1730 & $\begin{array}{l}\text { Solicitó a Merlo acordar con cabildo eclesiástico por nombrar sede } \\
\text { parroquial a su parroquia }\end{array}$ \\
\hline $\begin{array}{l}\text { Miguel de } \\
\text { Salcedo }\end{array}$ & 1738 & $\begin{array}{l}\text { Realizó a pedido de Merlo un informe al rey sobre utilidad de construir un } \\
\text { pueblo de españoles. Estuvo en la estancia de Merlo }\end{array}$ \\
\hline $\begin{array}{l}\text { Miguel de } \\
\text { Salcedo }\end{array}$ & 1741 & Reiteró el informe ante un nuevo pedido de Merlo. \\
\hline $\begin{array}{l}\text { Miguel de } \\
\text { Salcedo }\end{array}$ & 1742 & Reiteró el informe ante la solicitud de Merlo. \\
\hline $\begin{array}{l}\text { Domingo Ortiz } \\
\text { de Rosas }\end{array}$ & 1744 & $\begin{array}{l}\text { Recibió una Real Cédula en respuesta al pedido de Merlo. Se le previno } \\
\text { sobre la falta de información de las tierras para ejido. Debía informar al } \\
\text { Consejo de Indias. }\end{array}$ \\
\hline $\begin{array}{l}\text { José de } \\
\text { Andonaegui }\end{array}$ & 1749 & $\begin{array}{l}\text { Mandó realizar reconocimiento del lugar propuesto por Merlo para fundar } \\
\text { el pueblo a un Alguacil Mayor, un Piloto Práctico y el Escribano del } \\
\text { Cabildo. } \\
\text { Envió informe al rey con las respuestas solicitadas }\end{array}$ \\
\hline $\begin{array}{l}\text { José de } \\
\text { Andonaegui }\end{array}$ & 1754 & $\begin{array}{l}\text { Por Real Cédula se le indicó que se dedicara “con la mayor vigilancia y } \\
\text { aplicación" del formal establecimiento del "pueblo de españoles de } \\
\text { cincuenta familias que en la cercanía de la ciudad había solicitado hacer } \\
\text { don Francisco Merlo". Se le solicitó información sobre el curato y comunicó } \\
\text { que no se aceptaba la eximición de derechos parroquiales solicitada por } \\
\text { Merlo }\end{array}$ \\
\hline $\begin{array}{l}\text { José de } \\
\text { Andonaegui }\end{array}$ & 1755 & $\begin{array}{l}\text { Informó al rey lo actuado en el fomento del pueblo. Propuso nombre de la } \\
\text { población, "Villa de San Antonio del Camino". Informó sobre la erección } \\
\text { del curato, que había } 24 \text { familias en el paraje (aunque Merlo continuaría } \\
\text { hasta 50), y el nombramiento de un juez y un capitán, faltando la } \\
\text { aprobación real. Señaló lo beneficioso de la construcción de un Seminario } \\
\text { en el lugar. }\end{array}$ \\
\hline
\end{tabular}

Fuente: Elaboración personal a partir de TORRE REVELLO, José Los orígenes..., cit.

El proceso de solicitud de permiso real emprendido por Merlo representa en su conjunto una expresión de su realización como súbdito. Las actuaciones de los gobernadores parecieran centrales en la mayor o menor fluidez de la comunicación con la Corona, más allá de los vínculos institucionales-personales y las posibilidades económicas de Merlo. A la vez, varias de las propuestas

22 URBINA BURGOS, Rodolfo y LORENZO, Santiago La política de poblaciones...", cit. Para un enfoque comparativo, CANEDO, Mariana “Los pueblos de españoles...", cit. 
presentadas en primera persona por el gobernador Andonaegui a la Corona fueron originariamente realizadas por Merlo al gobernador (el nombramiento de las autoridades, el padrón sobre la población, el nombre del asentamiento, la propuesta de construcción del Seminario, etc.).

Francisco Merlo murió en la ciudad de Buenos Aires en 1758, a tres años de la confirmación real del permiso para la construcción de un pueblo que no se consolidó. Su hijo, el fraile mercedario Juan Antonio Merlo, quedó bajo la administración del proyecto que parecería había entrado en un período de estancamiento o declive.

\section{Solicitud de merced por terreno para pueblo}

La ocupación de terrenos por parte de pobladores a quienes no se los consideraba propietarios, o carecían de una relación de arrendatarios o agregados, ha sido destacada por su extendida presencia y la complejidad de sus derechos tanto por los estudiosos del derecho indiano como en la historiografía rural hispanoamericana. ${ }^{23}$ Menos conocido resulta que los ocupantes rurales hayan impulsado de manera conjunta la materialización de un pueblo de españoles. El caso del Rincón de San Pedro, ubicado a unas cuarenta leguas al norte de la ciudad de Buenos Aires, ejemplifica este modelo particular de formación de pueblos y particularmente del accionar jurídicopolítico con tal fin. ${ }^{24}$

Hacia mediados del siglo XVIII, la rinconada frente al río Paraná se encontraba poblada y en plena producción agrícola y ganadera. Se reconocían en ella propietarios particulares de terrenos, aunque también perduraba la tierra realenga. ${ }^{25}$ En 1780 se estableció el curato y cinco años después el partido,

23 Entre los primeros trabajos de reconocimiento de derechos de los ocupantes en Hispanoamérica se encuentra OTS CAPDEQUI, José María El régimen de la tierra en la América Española durante El período colonial, Trujillo, Universidad de Santo Domingo, 1946. Desde la historia rural, entre muchos otros, puede consultarse para el caso de Buenos Aires a FRADIN, Raúl "Ley, costumbre y relaciones sociales en la campaña de Buenos Aires (siglos XVIII y XIX)", en La ley es tela de araña. Ley, justicia y sociedad rural en Buenos Aires, 1780-1830, Prometeo, Buenos Aires, 2009, pp. 121-158.

${ }^{24}$ El caso ha sido desarrollado desde otras problemáticas en CANEDO, Mariana "¿Qué fueron los terrenos "del Pueblo"? Conformación y límites en los derechos por la tierra en pueblos de Buenos Aires, 1740-1860", en BONAUDO, Marta y RICHARD-JORBA, Rodolfo (comps.) Historia Regional. Enfoques y articulaciones para complejizar una historia nacional, Universidad Nacional de La Plata, La Plata, 2014, pp. 59-74 y de la misma autora, “Ocupantes espontáneos y derechos por la tierra en la formación de 'pueblos de españoles'. (Buenos Aires, Rincón de San Pedro, 1740-1860)", Revista Quinto Sol, vol. 19 (2), 2015, pp. 1-24

${ }^{25}$ Facultad de Filosofía y Letras, Documentos para la Historia Argentina, Buenos Aires, Compañía Sudamericana de Billetes de Banco, 1914, X, pp.560-566; DI STEFANO, Roberto Un rincón de la campaña rioplatense colonial. San Pedro durante la primera mitad del siglo XVIII. Cuadernos del 
ambos denominados del Rincón de San Pedro. El proceso de conformación del pueblo de españoles en la rinconada quedó específicamente documentado a partir de la solicitud de una merced realizada por 25 "vecinos" al virrey del Río de la Plata por el terreno que venían ocupando. ${ }^{26}$

Estos "vecinos", ocupantes de tierra realenga de manera continua, presentaban mayoritariamente rasgos de cierta notabilidad para la zona a principios del siglo XIX: algunos fueron autoridades o funcionarios locales, estuvieron censados como hacendados o pulperos, distinguidos como don o doña, contaron con algún esclavo, varios tenían origen europeo, y algunos fueron considerados propietarios de terrenos cercanos. ${ }^{27}$ En 1802, fueron representados por el comandante Fernando de Albandea, poblador en la zona, con experiencia en litigar sobre estos temas y con información precisa sobre la situación de realengo del terreno solicitado. Sin embargo, el proceso seguido para obtener el terreno fue más extenso, como puede verse en el siguiente cuadro.

\section{Cuadro 3}

\section{Solicitudes conducentes a la obtención del terreno para pueblo en San Pedro}

\begin{tabular}{|c|c|c|c|c|c|}
\hline AÑO & SOLICITANTE & SOLICITUD & JUSTIFICACIÓN & $\begin{array}{l}\text { SERVICIO/ } \\
\text { COMPROMISO }\end{array}$ & RESOLUCIÓN \\
\hline 1743 & $\begin{array}{l}\text { Cura rector y } \\
\text { doctrinero de la } \\
\text { reducción de } \\
\text { indios del } \\
\text { Baradero y del } \\
\text { curato de } \\
\text { Arrecifes }\end{array}$ & $\begin{array}{l}\text { Al rey. Permiso } \\
\text { para fundar } \\
\text { convento de } \\
\text { frailes recoletos }\end{array}$ & $\begin{array}{l}\text { Aumento cantidad } \\
\text { feligreses. Extenso } \\
\text { territorio. Frailes } \\
\text { accederían a } \\
\text { alimentación por } \\
\text { labradores- } \\
\text { pescadores de la } \\
\text { rinconada }\end{array}$ & $\begin{array}{l}\text { Terreno y } \$ 10.000 \\
\text { para construcción }\end{array}$ & 1750 \\
\hline $\begin{array}{l}\text { ca. } \\
1780\end{array}$ & $\begin{array}{l}\text { "Vecinos" del } \\
\text { Rincón }\end{array}$ & $\begin{array}{l}\text { Al obispo Malvar } \\
\text { y Pinto. Solicitud } \\
\text { de un cura y } \\
\text { capilla }\end{array}$ & $\begin{array}{l}\text { Se estableció nuevo } \\
\text { curato. }\end{array}$ & $\begin{array}{l}\text { Sostenimiento } \\
\text { económico }\end{array}$ & Se realizó \\
\hline 1802 & $\begin{array}{l}\text { Teniente } \\
\text { General de } \\
\text { Milicias del } \\
\text { Rincón de San } \\
\text { Pedro, Fernando } \\
\text { Albandea y } 24 \\
\text { vecinos más. }\end{array}$ & $\begin{array}{l}\text { Al virrey Joaquín } \\
\text { del Pino. } \\
\text { Designación del } \\
\text { terreno que } \\
\text { habitaban. }\end{array}$ & $\begin{array}{l}\text { Poblamiento } \\
\text { continuo. Han } \\
\text { logrado darle figura } \\
\text { de pueblo. Se } \\
\text { lograría } \\
\text { asentamiento y } \\
\text { construcciones más }\end{array}$ & $\begin{array}{l}\text { Sostenimiento } \\
\text { económico de la } \\
\text { capilla, el cura y } \\
\text { el convento. } \\
\text { Beneficiaban a las } \\
\text { Administraciones }\end{array}$ & $\begin{array}{l}1802 \\
\text { providencia } \\
\text { del virrey para } \\
\text { posesión del } \\
\text { terreno }\end{array}$ \\
\hline
\end{tabular}

Instituto Ravignani, 1, Buenos Aires: Universidad de Buenos Aires, 1991; CANEDO, Mariana “QQué fueron los terrenos...", cit.

26 El extenso expediente sobre la solicitud del terreno fue tratado con detalle en CANEDO, Mariana, “¿Qué fueron los terrenos...", cit y “Ocupantes espontáneos...”, cit.

27 CANEDO, Mariana “Ocupantes espontâneos...", pp.11-15. 


\begin{tabular}{|c|c|c|c|c|c|}
\hline & & & $\begin{array}{l}\text { estables. Abierto a } \\
\text { quien quisiera } \\
\text { poblar. }\end{array}$ & $\begin{array}{l}\text { reales de Tabaco y } \\
\text { Naipes, y de } \\
\text { Correos de la } \\
\text { zona. }\end{array}$ & \\
\hline 1802 & $\begin{array}{l}\text {-Marcos Zelis } \\
\text {-Agrimensor } \\
\text { Alsina en } \\
\text { nombre de } \\
\text { familia } \\
\text { Benavidez }\end{array}$ & $\begin{array}{l}\text { Al virrey. } \\
\text { Apelaciones a la } \\
\text { providencia. }\end{array}$ & $\begin{array}{l}\text { Cada uno } \\
\text { consideraba que era } \\
\text { propietario de parte } \\
\text { del terreno solicitado } \\
\text { en merced. } \\
\text { Cuestionamientos } \\
\text { personales a } \\
\text { Albandea }\end{array}$ & & $\begin{array}{l}1803 \\
\text { Confirmación } \\
\text { de la } \\
\text { providencia } \\
\text { sobre terreno } \\
\text { realengo }\end{array}$ \\
\hline 1806 & $\begin{array}{l}\text { Alcalde, } \\
\text { comandante y } \\
\text { cura }\end{array}$ & $\begin{array}{l}\text { Al virrey. } \\
\text { Aprobación del } \\
\text { plano del pueblo }\end{array}$ & $\begin{array}{l}\text { Solicitado por el } \\
\text { virrey en } 1802\end{array}$ & & $\begin{array}{l}\text { Diciembre de } \\
1806 \\
\text { aprobación }\end{array}$ \\
\hline 1806 & $\begin{array}{l}\text { Alcalde, } \\
\text { comandante y } \\
\text { cura }\end{array}$ & $\begin{array}{l}\text { Al virrey. } \\
\text { "Adelantamiento } \\
\text { (...) Villa de San } \\
\text { Pedro" }\end{array}$ & $\begin{array}{l}\text { Asentamiento para } \\
\text { familias ante "las } \\
\text { fatalidades y } \\
\text { desgracias de la } \\
\text { Capital" }\end{array}$ & $\begin{array}{l}\text { Sin costo para las } \\
\text { familias } \\
\text { migrantes }\end{array}$ & $\begin{array}{l}\text { Diciembre } \\
1806 \text { se reserva } \\
\text { resolución } \\
\text { para "ocasión } \\
\text { más oportuna" }\end{array}$ \\
\hline $\begin{array}{l}1806 \\
\text { dic. }\end{array}$ & $\begin{array}{l}\text { Comisionado } \\
\text { por virrey a } \\
\text { autoridades } \\
\text { locales }\end{array}$ & $\begin{array}{l}\text { No cobro de } \\
\text { derechos de } \\
\text { asentamiento }\end{array}$ & $\begin{array}{l}\text { Fomentar en el } \\
\text { pueblo el } \\
\text { asentamiento de la } \\
\text { población }\end{array}$ & & \\
\hline
\end{tabular}

Fuente: MOP, “Don Fernando Albandea por sí...", cit.

Diferentes actores intervinieron en los procesos de conformación del pueblo, instalación del convento y la capilla, y establecimiento de las jurisdicciones, como puede inferirse del cuadro. Sin embargo, la ocupación del terreno por parte de los pobladores, antes y después del pedido de merced, junto con el sostenimiento económico del convento, la parroquia y las administraciones reales, constituyeron los fundamentos para realizar los pedidos a la corona.

Iniciada la solicitud en conjunto por los vecinos, las autoridades locales del partido y curato de San Pedro -que también eran vecinos- impulsaron la consolidación de derechos. En todo el proceso hubo oportunidades que fueron aprovechadas: el conocimiento de la situación de realengo del terreno por parte de Albandea en 1802, la solicitud conjunta de los ocupantes de la merced y una inmediata providencia del virrey, la realización del plano por parte de un piloto en tránsito y la aprobación por parte del virrey en 1806. El proceso en su 
conjunto fue de más larga duración, avanzando hasta la segunda mitad del siglo XIX, pero fue durante estos años que se establecieron los derechos. ${ }^{28}$

\section{Tensiones en el devenir de pueblo de indios a pueblo de españoles}

La conformación de un pueblo de españoles a partir de uno "de indios" fue un camino recorrido en diferentes zonas de Hispanoamérica. Para Buenos Aires, sin embargo, Santiago de Baradero fue uno de los pocos asentamientos que, conformado como reducción en el siglo XVII, pervivió como pueblo de indios durante todo el siglo XVIII. La complejidad que implicó su transformación a pueblo de españoles se pone de manifiesto en las tensiones que se generaron para desarticular los privilegios corporativos del pueblo de indios tanto como para protegerlos. Presentamos a continuación algunas situaciones generadas en torno al pueblo en las últimas décadas del siglo XVIII, que ejemplificar cómo se fue produciendo la transformación. ${ }^{29}$

Hacia 1780, el obispo de Buenos Aires, Sebastián Malvar y Pintos, se dedicó a vitalizar la situación de los curatos y parroquias en la jurisdicción por lo que recorrió pueblos de indios y de españoles. Realizó informes y propuso modificaciones que quedaron plasmados en su correspondencia con el virrey Juan José Vértiz y Salcedo. Específicamente sobre el "curato de indios de Baradero", el obispo consideró que debía ser abolido y "subrogado al de españoles". Su interpretación de la situación quedó así plasmada:

"los pocos indios que hoy se conservan en aquel paraje o son transmigrados de Santiago del Estero, Misiones y otras partes, o mulatos del partido de los Arroyos; todos (...) incapaces de alimentar curas; y, por otra parte, los españoles (...) quieren hacer parroquia, siempre que a la antigua se le saque el nombre de parroquia de indios" ${ }^{30}$

El panorama brindado sobre la composición socio-demográfica del pueblo resulta congruente con la que hemos analizado en otra oportunidad considerando padrones y listas tributarias de la población de Baradero, que no se diferenciaba de las tendencias de otros pueblos de indios hacia fines del siglo

\footnotetext{
28 Sobre la continuidad de los procesos de consolidación de derechos, ver CANEDO, Mariana "Ocupantes espontáneos...", cit.

${ }^{29}$ Santa Cruz de los Quilmes fue otro de los pueblos de indios en Buenos Aires que tuvo una evolución similar en Buenos Aires. Referimos a los estudios de SORS, Guillermina Quilmes colonial, La Plata, Archivo Histórico de la Provincia de Buenos Aires, 1937; SANTILLI, Daniel Quilmes. Una Historia Social, Buenos Aires, El Monje Editor, 2010. Para un enfoque comparativo entre ambos pueblos y el pueblo de Santo Domingo Soriano, ver CANEDO, Mariana "Los pueblos de españoles...", cit.

${ }_{30}$ Citado por PICCAGLI, Américo y TAURIZANO, Zulma Historia documental de San Pedro, Rafael \&Armas Asociados, Buenos Aires, tomo 1, 1986, p.123.
} 
XVIII. ${ }^{31}$ El sesgo en la perspectiva del obispo se expresaba claramente en la preocupación sobre el sostenimiento económico de representantes del culto católico en el pueblo. Pero además, profundizaba sus propuestas cuestionando los privilegios medulares del pueblo de indios en tanto corporación territorial con jurisdicción y gobierno propio:

“no podrán pretender preferencias de asientos en la iglesia de españoles, ni en los procesos y más funciones públicas, ni se llamaría iglesia de indios, sino de españoles, y si a V.E. le pareciera conveniente disolverá también el nombre de Alcalde de indios haciendo que todos queden sujetos a la justicia ordinaria, y que puedan poblar allí los que quieran" 32

Los cuestionamientos a la autoridad del pueblo de indios aumentaron hacia fines de siglo, fundamentalmente cuando quien había sido elegido alcalde fue acusado de asesinato y se convirtió en prófugo. En 1785, el virrey intervino mandando un comisionado a realizar un informe sobre la situación. Entre otras cuestiones, el informe derivó en la indagación sobre el origen y las dimensiones del terreno del pueblo del Baradero, sobre lo que no se encontró documentación. ${ }^{33}$ En 1790, el cabildo de Buenos Aires se referirá al pago de Santiago de Baradero como "pueblo y curato de Indios y Españoles".

En 1800, 53 "naturales" del pueblo pidieron al protector de indios que se presentara ante el virrey por la restitución de "nuestros privilegios" otorgados por el rey a "nuestros antecesores" y la expulsión de los "españoles intrusos" del pueblo. Los privilegios a recuperar eran "los terrenos", "formar cabildo" y elegir su alcalde. También proponían formar una compañía de naturales y volver a pagar tributo. ${ }^{34}$

Para el pueblo de indios del Baradero no se produjo un decreto sobre la supresión de los privilegios como sí hizo el Triunvirato posrevolucionario de 1812 para el pueblo de los Quilmes. En dicha disposición, en un contexto

31 CANEDO, Mariana "Tensiones en los pueblos de indios. Dinámicas poblacionales, corporativas y de poder. (Santiago de Baradero, Buenos aires, siglos XVIII-XIX)", presentada en $V$ Reunión del Comité Académico "Historia, Regiones y Fronteras", Asociación Universidades del Grupo Montevideo, Mar del Plata, 24-26 de abril, 2014.

${ }^{32}$ Citado por PICCAGLI, Américo y TAURIZANO, Zulma Historia documental..., cit., p.124 El destacado es nuestro.

${ }^{33}$ Archivo General de la Nación (en adelante AGN), Buenos Aires, IX, 1-4-2.

${ }^{34}$ Ante solicitudes específicas realizadas por los indios, continuaron surgiendo reacciones que se focalizaban en cuestionar sus privilegios. Así, por ejemplo, en 1803 el cacique Cornelio Aguirre señalaba que era "uso y costumbre el feriar el Patrono, como lo hacen los demás Pueblos, Villas y Ciudades", y el cura rechazaba el pedido por considerar que no eran "indios" quienes habitaban en el pueblo. La intervención del protector consistió en un pedido de informe a la Contaduría de Retasas sobre tributarios matriculados en los últimos años. También en 1805, se solicitó nuevamente la documentación sobre "los terrenos de la reducción", que no fue encontrada. AHPBA, La Plata, Cuerpo 13, 2-7-28 bis, Escribanía Mayor de Gobierno. 
también de presiones y resistencias sobre las jurisdicciones del pueblo de indios se derogaron "todos los derechos y privilegios que gozaban los pocos indios que existen en dicha población". ${ }^{35}$ Sin necesidad de decreto, en Baradero se comenzó a considerar un único pueblo sin distinción jurisdiccional. En 1815, se realizó un censo para toda la campaña en el que se registraron 103 personas agrupadas en 23 unidades viviendo en el pueblo: la mitad encabezadas por "blancos" o "españoles" y las restantes por "indios", "mestizos" y "pardos". ${ }^{36}$

\section{Fundación de una "villa" en la jurisdicción de Buenos Aires}

El establecimiento de pueblos impulsados directamente por autoridades, particularmente por virreyes, fue una modalidad que encontramos en Buenos Aires en los primeros años del siglo XIX: el marqués de Avilés promovió la constitución de la Villa de la Ensenada de Barragán (1801) y el marqués de Sobremonte, la Villa de San Fernando de la Bella Vista (1805). Cada caso tuvo sus propias modalidades y contextos, pero ambos compartieron, además de haber sido promovidos a partir de las decisiones de los virreyes, ser asentamientos ubicados frente a ríos y vinculados al creciente comercio fluvial de fines del siglo XVIII, haber sido proyectados como "villas" desde los primeros pasos constitutivos, y no lograr dicha titulación. Otra característica en común es haber tenido litigios planteados fundamentalmente en términos de potestades jurisdiccionales, y que los mismos fueran resueltos en el Consejo de Indias. Nos detendremos, sintéticamente, en el caso de San Fernando de la Bella Vista. ${ }^{37}$

En 1805, hubo una importante creciente del Río de la Plata que generó destrozos en la ribera de Buenos Aires y "la destrucción casi total del pueblo" de Las Conchas. Este pueblo había surgido hacia 1770 a partir del puerto homónimo intermediario en el comercio entre Asunción y Buenos Aires. El cabildo de Buenos Aires y el virrey Sobremonte, en base a los informes del síndico procurador, el comandante y el cura, decidieron trasladar la población

\footnotetext{
${ }^{35}$ Reproducido por SORS, Guillermina, Quilmes..., cit. Sobre las diferencias interpretativas ante disputas por "las jurisdicciones", clásicamente consideradas por la "tierra" véase GARCÍA MARTÍNEZ, Bernardo "Jurisdicción y propiedad: una distinción fundamental en la historia de los pueblos de indios del México colonial", en European Review of Latin American and Caribbean Studies, 53, 1992, pp. 47-60.

36 AGN, IX, 9-7-6 Las unidades censales encabezadas por "indios" fueron seis, tres de "mestizos" y dos de "pardos".

${ }^{77}$ CANEDO, Mariana "La fundación de villas como encrucijada de intereses en la monarquía hispánica. Autoridades, corporaciones y relaciones interpersonales en el Río de la Plata (18001807)", HISTORelo. Revista regional y local, Universidad Nacional de Colombia, Medellín, en prensa. La consolidación de los pueblos de San Fernando y Las Conchas son abordados en CANEDO, Mariana "Pueblos frente al río. Comercio fluvial, poder colonial, y derechos a la tierra Buenos Aires, 1770-1820", en Bibliográphica Americana. Revista interdisciplinaria de Estudios coloniales, núm. 8, 2012, pp.69-93.
} 
existente a una zona alta inmediata conocida como Punta Gorda, donde ya había algunos pobladores. Sobremonte contaba con experiencia en el fomento de fundación de villas, ya que como gobernador intendente de Córdoba del Tucumán había experimentado la complejidad de estos procesos. ${ }^{38}$ En esta oportunidad, motorizó la construcción de un canal próximo a la nueva población que resultaba de una envergadura regionalmente importante. Las modalidades empleadas para contar con recursos y financiamiento para realizarlo, así permiten considerarlo.

\section{Cuadro 4}

\section{Medidas tomadas para la construcción del canal frente a San Fernando}

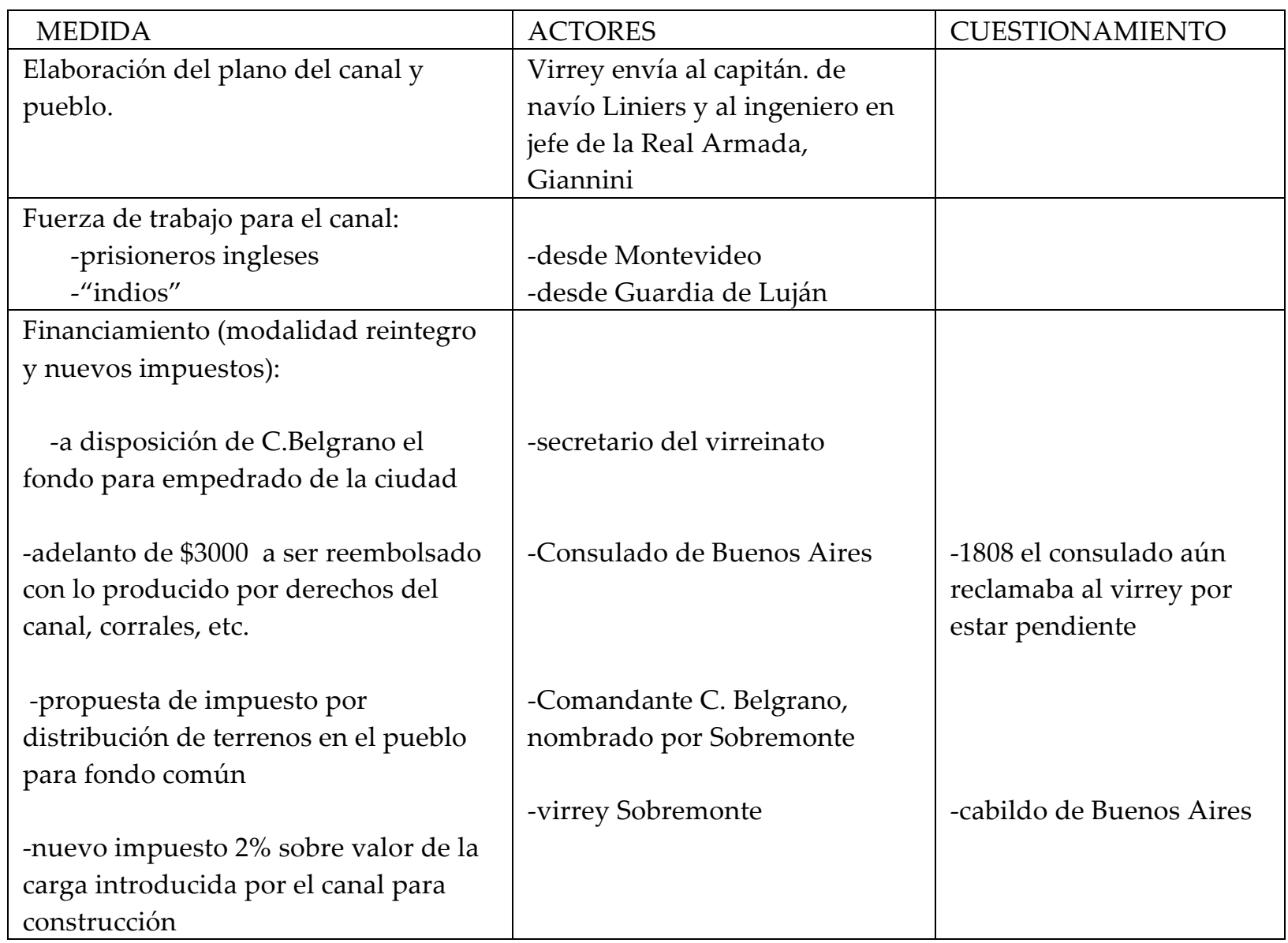

Fuente: AGN, IX, 7-3-6-8. Obra Pública, Canal de San Fernando, 1770-1806. TJARKS, Germán El Consulado de Buenos Aires y sus proyecciones en la historia del Río de la Plata. Buenos Aires, Universidad de Buenos Aires, Buenos Aires, 1962; UDAONDO, Enrique Reseña Histórica del Partido de Las Conchas. AHPBA, La Plata, 1942; CANEDO, Mariana "Pueblos frente al río.", cit.

En el cuadro se evidencia que tras la decisión de trasladar la población del pueblo de Las Conchas, el cabildo de Buenos Aires quedó por fuera de los

38 PUNTA, Inés Córdoba borbónica..., cit.; RUSTÁN, Elizabeth Las políticas de frontera.., cit. El fomento a la conformación de villas por parte de Sobremonte en Buenos Aires también se expresó en la providencia dictada en 1806 donde dispuso llevar a cabo una traza para el "Pueblo de San Salvador de Lobos" en el terreno otorgado en merced a beneficio del cura vicario en una zona que contaba con un millar de labradores. 
vínculos articulados por Sobremonte para lograr fuerza de trabajo y dinero para financiar las obras. Es más, a principios de 1806, el virrey comunicaba al cabildo de Buenos Aires desde Montevideo su decisión de erigir en villa a la nueva población denominada "San Fernando de Buena Vista". ${ }^{39}$ En el siguiente cuadro sintetizamos decisiones tomadas para la construcción de la villa y las reacciones que generaron.

\section{Cuadro 5}

\section{Medidas dispuestas para la conformación de la villa de San Fernando (1806)}

\begin{tabular}{|c|c|c|}
\hline MEDIDAS & ACTORES & CUESTIONAMIENTO \\
\hline $\begin{array}{l}\text { Comunica la propuesta de } \\
\text { titulación de la nueva población } \\
\text { como villa al cabildo de Buenos } \\
\text { Aires }\end{array}$ & Virrey Sobremonte & $\begin{array}{l}\text { Cabildo de Buenos Aires al } \\
\text { Consejo de Indias }\end{array}$ \\
\hline $\begin{array}{l}\text { Padrón con pobladores ( } 300 \\
\text { habitantes) }\end{array}$ & $\begin{array}{l}\text { Comandante } \\
\text { Belgrano }\end{array}$ & \\
\hline $\begin{array}{l}\text { Nombramiento de Belgrano como } \\
\text { Ayudante Mayor de la nueva villa } \\
\text { y director de las obras del canal }\end{array}$ & Virrey Sobremonte & \\
\hline $\begin{array}{l}\text { Distribución de terrenos solares, } \\
\text { quintas y chacras }\end{array}$ & $\begin{array}{l}\text { Comandante } \\
\text { Belgrano }\end{array}$ & $\begin{array}{l}\text { Mariano Moreno, abogado en } \\
\text { representación antiguos } \\
\text { pobladores, por "desalojo" y } \\
\text { "requisiciones de autoridad". } \\
\text { Intento de acuerdo fracasado. } \\
\text { Consejo de Indias rechaza } \\
\text { acusaciones en } 1807\end{array}$ \\
\hline $\begin{array}{l}\text { Traslado a San Fernando del } \\
\text { virrey y séquito: colocación piedra } \\
\text { basal iglesia e inicio simbólico del } \\
\text { canal }\end{array}$ & $\begin{array}{l}\text { Virrey, virreina y } \\
\text { séquito }\end{array}$ & \\
\hline $\begin{array}{l}\text { Narración grandilocuente en } \\
\text { número extraordinario del } \\
\text { periódico }\end{array}$ & $\begin{array}{l}\text { Semanario de } \\
\text { Agricultura, Industria } \\
\text { y Comercio }\end{array}$ & $\begin{array}{l}\text { Cabildo de Buenos Aires, "capaz } \\
\text { de sorprender al no instruido de } \\
\text { lo que es aquello } \\
\text { verdaderamente". }\end{array}$ \\
\hline
\end{tabular}

Fuentes: Semanario de Agricultura, Industria y Comercio, Buenos Aires, Junta de Historia y Numismática Americana. Tomos IV y V, 1938, febrero 1806; CORDERO, Héctor Carlos Belgrano, cit.; CANEDO, Mariana "Pueblos frente al río.", cit.

En otra oportunidad, nos hemos detenido en el cuestionamiento realizado por el abogado Mariano Moreno en representación de los antiguos pobladores por derechos a los terrenos y el accionar del Comandante Carlos Belgrano. ${ }^{40}$ En el próximo apartado sintetizaremos la reacción del cabildo de Buenos Aires ante la decisión del virrey de otorgar el privilegio de constituir en villa a la nueva población, junto con pedidos análogos para otros pueblos.

${ }^{39}$ CORDERO, Héctor Carlos Belgrano, Ediciones Delta, Buenos Aires, 1968

${ }^{40}$ CANEDO, Mariana "Pueblos frente al río...", cit. 


\section{Las solicitudes para ser villa en Buenos Aires}

Los pueblos de españoles analizados, lo hemos adelantado, no lograron acceder a los privilegios propios de ser villas y fueron considerados comunidades imperfectas, siguiendo el planteo elaborado por Francisco Suarez al que ya hemos hecho referencia. ${ }^{41}$ La importancia de esta distinción entre comunidades reside, para la problemática que estamos abordando, en que la atribución de prerrogativas políticas quedaba condicionada: las comunidades imperfectas necesitaron de un acto de aprobación por parte del rey para dejar de serlo, o del reconocimiento de la costumbre. El otorgamiento del privilegio se concedía caso por caso y constituía un instrumento de fortalecimiento de las relaciones de poder entre la parte que solicitaba y la que otorgaba. ${ }^{42}$ Aunque algunos lo pretendieron, los pueblos de españoles de la jurisdicción de Buenos Aires analizados, no lograron ser villas porque no obtuvieron el privilegio real.

¿Por qué se generaron estas negativas en un contexto de fomento de establecimiento de poblaciones por parte de la monarquía a partir de sus disposiciones? Las intenciones expresadas desde los pueblos por ser villas, permiten señalar características de las peticiones y los fundamentos de las respuestas de las autoridades.

A diferencia de las poblaciones fundadas como villas o ciudades que ya nacieron con prerrogativas determinadas, las solicitudes a la titulación de villa se hicieron, en los pueblos que analizamos, tras haber logrado otros privilegios como el reconocimiento del terreno para el asentamiento o la aprobación del plano correspondiente, y la constancia de la presencia de pobladores. Al igual que otras solicitudes a la gracia real, los pedidos estuvieron fundamentados en méritos y servicios de los súbditos que lo propusieron (en términos grupales o personales) de la misma manera que lo habían estado la solicitud de permiso real para construir un pueblo realizada por Merlo, la petición de un terreno para pueblo en merced realizada por los veinticinco vecinos del Rincón de San Pedro, o la solicitud de los 53 "naturales" del pueblo de Baradero para la restitución de sus privilegios. ${ }^{43}$

\footnotetext{
${ }^{41}$ Los privilegios de las villas y las ciudades variaron según las jerarquías de cada una, las necesidades de la monarquía, y la articulación de posibles solapamientos de privilegios con otros cuerpos territoriales, entre otras cuestiones. Sin embargo, implicaron el derecho a conformarse (en caso de ser fundaciones), contar con gobierno propio, en el sentido de poder ser gobernados por autoridades elegidas por los vecinos de cada asentamiento, y diferentes niveles de jurisdicción. ROJAS, Beatriz "Repúblicas de españoles:...", cit.

42 HESPANHA, Antonio Manuel Direito Luso-Brasileiro..., cit; AGÜERO, Alejandro "Ciudad y poder político...", cit; GAYOL, Victor "Colofón", cit.

${ }^{43}$ Según señala Beatriz Rojas, los servicios de los súbditos habrían sido más valorados en Hispanoamérica que en la península ibérica y los aportes económicos hacia la corona parecen haber sido centrales al avanzar el siglo XVIII.
} 
Francisco Merlo, por lo que conocemos, no llegó a solicitar la titulación de villa para el pueblo que propuso realizar. La Real Cedula de 1755 impulsaba a Merlo para que "continúe y acabe la construcción del Pueblo de Españoles que tiene ofrecido a S.M y principiado en el Pago de las Conchas, el cual dicho Pueblo se nombrará desde ahora la Villa de San Antonio del Camino". ${ }^{4}$ Sin embargo, cuando Merlo realizó el edicto para convocar a más pobladores, se refirió a "esta Villa de San Antonio del Camino" y se presentó como “Dueño de esta villa". ${ }^{45}$ Esta denominación, que posiblemente buscara prestigiar al asentamiento, no tuvo correspondencia con las características del gobierno local.

En el caso del pueblo de San Pedro, la posibilidad de ser villa se consideró ya en la providencia realizada ante el pedido del terreno, al señalar el virrey la importancia de guardar "el orden correspondiente" para que en lo sucesivo se dispusiera "la fundación de una formal Villa con los requerimientos dispuestos en las Leyes del Reyno". ${ }^{46}$ Sin embargo, el requisito de presentar un plano del terreno se concretó recién en noviembre de 1806 cuando el contexto político había cambiado en el Río de la Plata. ${ }^{47}$ En junio de ese año, una flota inglesa con unos 1.500 hombres había tomado el control de la ciudad de Buenos Aires. Tras un inédito proceso de movilización de la población en ambas orillas del Río de la Plata, en agosto se había logrado hacer capitular a los invasores. El resquebrajamiento de las relaciones de poder fue notorio durante esos meses. Ante la ocupación inglesa, el virrey Sobremonte había abandonado la ciudad con su guardia y los caudales del tesoro, y las principales corporaciones de la monarquía hispánica con sede en la ciudad capital se habían rendido, jurando fidelidad a los ingleses. Como contraparte del desprestigio alcanzado por estos, el oficial de Armada Real Santiago Liniers, los jefes milicianos y el cabildo de Buenos Aires habían salido fortalecidos. Un cabildo abierto influenciado por una amplia movilización, rechazó el regreso del virrey Sobremonte, nombrando a Liniers como comandante encargado de organizar la defensa. La nota de las autoridades de San Pedro fue dirigida al "Señor Regente y Gobernador en lo Político" y la respuesta fue firmada por Liniers (antes de la segunda invasión)

\footnotetext{
${ }^{44}$ Como adelantamos, la propuesta del nombre había sido realizada por Merlo al gobernador y de este al Consejo de Indias, pero solo se incorporaba Villa como denominación.

${ }^{45}$ CANEDO, Mariana Poderes intermedios...

${ }^{46} \mathrm{MPO}$, “Don Fernando Albandea por sí...", cit., f 4r

${ }^{47}$ La demora en la realización se explicó por "no haberse proporcionado desde aquella fecha sujeto inteligente para la delineación del pueblo y formación del Plano", y el costo de traerlo desde la ciudad de Buenos Aires, se argumentaba, habría sido demasiado para los vecinos. La mensura realizada en noviembre de 1806, "desinteresadamente" por este piloto que se hallaba en el falucho San Luis en el "Puerto de San Pedro" es particular. Se centra en describir la barranca, el clima, el suelo y las posibilidades económicas de la zona. MPO, "Don Fernando Albandea por sí...", cit., f 35 .
} 
Al presentar el plano, las autoridades locales (el alcalde de la Santa Hermandad, el cura y el teniente) hicieron varias referencias a "esta nueva Villa": pedían que la autoridad del virreinato dispusiera las "órdenes convenientes" y esperaban que tomase "particular interés" para "el adelantamiento de esta nueva Villa de San Pedro". La fundamentación del pedido, como hemos señalado, se basaba en "la libertad" con que las familias podrían ir a situarse en ella y "sin costo alguno". Se lograría, señalaban las autoridades locales, proteger a muchas de ellas de "las presentes fatalidades y desgracias de la Capital han dispensado y andan errantes por estas campañas", en referencia a la movilización generada por la invasión inglesa. ${ }^{48}$

Como respuesta, se aprobó el plano y se señalaron procederes sobre la "formación de edificios" que serían supervisados por "el Teniente y el Alcalde". Por "comisión del virrey" se reservó "para ocasión más oportuna, la erección y establecimiento de Villa que solicitan aquellos interesados". ${ }^{49}$

En el caso de San Fernando, unos meses antes de la invasión de los ingleses el propio virrey Sobremonte comunicó al cabildo de Buenos Aires, como hemos expuesto, su decisión de erigir en villa a la nueva población. Desde Montevideo, expresaba que había mandado realizar la conformación del cabildo "luego que se reúna el vecindario, y se componga de individuos que puedan obtener cargos concejiles". ${ }^{50}$ Unos días antes de la presencia inglesa, el cabildo comunicó su disconformidad ante la decisión del virrey al Consejo de Indias, considerando que Sobremonte había extendido sus disposiciones por fuera "de la líneas de su autoridad". Por un lado, se cuestionaba que hubiese concurrido al lugar y hecho público la decisión en una "pomposa relación" publicada en el Semanario "capaz de sorprender al no instruido de lo que es aquello verdaderamente." ${ }^{51}$ Por otro, la crítica del cabildo se focalizaba en que no había sido considerado en las decisiones que eran de su potestad. Más aún, argumentaba que sería el propio cabildo quien debería colaborar con su mantenimiento, porque el pueblo "carece de los requisitos necesarios para su erección y necesita que la ciudad de Buenos Aires le preste cuantos recursos convenga para la subsistencia." ${ }^{52}$ Ante los impuestos que el virrey había

\footnotetext{
${ }^{48} \mathrm{MOP}$, “Don Fernando Albandea por sí...”, cit., f. 44

${ }^{49} \mathrm{MOP}$, “Don Fernando Albandea por sí...", cit., f 44r

${ }^{50}$ Citado por CORDERO, Héctor Carlos Belgrano..., cit. p.85

${ }^{51}$ CORDERO, Héctor Carlos Belgrano... pp. 84-85. En un número extraordinario del "Semanario de Agricultura, Industria y Comercio" se había hecho referencia a la ceremonia de colocación de la piedra basal a la iglesia y para dar comienzo simbólico a la construcción del canal, presidida por el virrey y la virreina con la presencia del sequito, de la compañía del Regimiento de Dragones con banda de música y "la orquestilla del indio Miguel". Se señalaba la colocación de "arcos triunfantes", y que el acto se habría celebrado entre "el estruendo de muchos y muy variados cohetes". Semanario de Agricultura, Industria y Comercio, Buenos Aires, número extraordinario de febrero 1806. CANEDO, Mariana "Pueblos frente al río...", cit.

${ }^{52}$ Citado por CORDERO, Héctor Carlos Belgrano..., cit. p.85
} 
incorporado al comercio con Paraguay y a la extracción de leña y madera del lugar, el cabildo le comunicaba al rey que las regalías y privilegios de la propia ciudad podían quedar expuestos a la voluntad del virrey.

Las invasiones inglesas detuvieron la construcción del canal, pero lo actuado sobre el asentamiento por Sobremonte -ya ex virrey- quedó aprobado con posterioridad, según comunicó el secretario del Consejo de Indias. La excepción fue la erección del pueblo en villa. ${ }^{53}$

Ahora bien, si bien reiterados, los cuestionamientos o rechazos a la conformación de villas no se dieron exclusivamente en la jurisdicción del cabildo de Buenos Aires. ${ }^{54}$ Un ejemplo, entre otros posibles, ubicado no muy distante de los casos analizados es el de algunos vecinos de la "Villa" del Paraná que en 1801 solicitaron la erección de su propio cabildo al de la ciudad de Santa Fe. El procurador señaló en su respuesta que no constaba que el pueblo fuese villa -como decían los "cuatro vecinos" que firmaban la nota- y la falta de vecinos que supiesen leer y que no estuviesen ya ocupando otros cargos, para integrar un cabildo propio. Se recordaba que ya había habido dificultad para elegir alcaldes de la hermandad en el pueblo del Paraná, y que se había tenido que nombrar a vecinos de Santa Fe. ${ }^{55}$

Sin embargo, en el caso de la "villa del Paraná" el procurador también reflexionaba que, como convenía al "estado la multiplicación y perfección de poblaciones", el cabildo de Santa Fe podía recomendar al gobierno superior que en caso de decidir hacer villa al pueblo del Paraná, solo se le diese "por término de jurisdicción una corta distancia en contorno de aquel lugar, quedándole a la

\footnotetext{
${ }^{53}$ CANEDO, Mariana "Pueblos frente al río...", cit.

${ }^{54}$ Para Nueva España, Beatriz Rojas señala que los primeros cambios en la política de la corona en cuanto a fundaciones y los privilegios de autogobierno se realizaron en el siglo XVI, lo que llevó a que se denegara en algunos casos la titulación de villa. Sin embargo, la influencia de los requerimientos económicos de la monarquía habrían revertido la situación. ROJAS, Beatriz "Repúblicas de españoles...", cit., p.24. Ejemplos de la dinámica de otorgamientos reales y rechazos de privilegios a ayuntamientos de españoles, repúblicas de indios y asentamientos de afrodescendientes pueden verse en GARCÍA RUIZ, Luis Juventino Una arena de conflictos..., cit. ${ }^{55}$ Actas del Cabildo de Santa Fe, Tomo XVII A, XVII $f 46$ v a $f 48,7$ de Septiembre de 1801. En línea, https://www.santafe.gob.ar/actascabildo/default/ficha/6040. Una descripción similar realizó Concolorcorvo sobre el cabildo de la Villa de Luján, la temprana excepción en la campaña de Buenos Aires: "Luján, tiene título de Villa, con poco más o menos sesenta vecinos, entre los cuales apenas hay dos capaces de administrar justicia, y así, regularmente, echan mano para alcaldes de los residentes del pago de Areco" CALIXTO BUSTAMANTE, Carlos Inca El lazarillo de ciegos caminantes desde Buenos Aires hasta Lima, Grao, Barcelona, 1973, p. 57. En este sentido puede leerse la indicación dada por Sobremonte sobre la conformación del cabildo en San Fernando cuando el vecindario se compusiera de individuos que pudieran obtener cargos concejiles.
} 
ciudad de Santa Fe la facultad expedita para nombrar jueces pedáneos y de comisión en lo demás partidos de aquella jurisdicción" ${ }^{56}$

El consejo no era menor. Los argumentos recogidos de los distintos casos, aunque breves, parecieran ir en el sentido dado por el procurador. Así como en el devenir del pueblo de indios a uno de españoles las tensiones se centraron en la desarticulación de las jurisdicciones existentes para construir otras, podemos considerar a la conformación de los pueblos de españoles como procesos de consolidación o ampliación de jurisdicciones, en el camino hacia constituirse como villa y poder conformar un gobierno propio, entre otras prerrogativas.

\section{Conclusiones}

La reconstrucción de los diversos caminos recorridos para la constitución de los pueblos de españoles como parte de la monarquía hispánica ha permitido considerar la dinámica política de estos procesos. Los privilegios reales no solo fueron una parte medular en la materialización de las villas y ciudades o en los pueblos de indios, sino también en otras comunidades consideradas imperfectas. Como sucedió en otras comunidades de Hispanoamérica, como "los libres de todo color" cuando sus poblados fueron considerados sitios, la obtención de la calidad de pueblos de españoles significó prerrogativas para sus pobladores en la campaña de Buenos Aires durante el siglo XVIII.

La solicitud de privilegios personales o grupales, a partir de exponer servicios realizados como súbditos a la corona y comprometerse a realizar otros, fue un mecanismo frecuente. En los casos analizados, se ejemplifica con la petición del permiso para la construcción de un pueblo por parte de Merlo, un vecino de la ciudad de Buenos Aires e integrante de la élite rioplatense, o ante el pedido de un terreno en merced por parte de un grupo de 25 vecinos que lo venían ocupando en el Rincón de San Pedro. A su vez, los casos también pusieron de manifiesto una modalidad de construcción del territorio y establecimiento de jurisdicciones con intervenciones de diferentes actores, que ajustaron y cuidaron sus pretensiones y derechos. Hemos señalado la búsqueda de acceso a un entramado de vínculos que eran a la vez personales e institucionales, los acuerdos negociados y que no faltaron las apelaciones y los desacuerdos.

Los conflictos y tensiones evidenciaron la importancia de consolidar los privilegios obtenidos y de apelar por parte de quienes consideraron afectadas sus propias prerrogativas ante nuevas solicitudes $u$ otorgamientos por parte de

\footnotetext{
56 Actas del Cabildo de Santa Fe, cit. Para profundizar el caso remitimos a POLIMENE, María Paula "El alcalde de la Hermandad del pago de Bajada entre 1784 y 1786. Autoridades locales y disputa jurisdiccionales", en: POLIMENE, María Paula Autoridades y práctica judiciales en el Antiguo Régimen. Problemas jurisdiccionales en el Río de la Plata, Córdoba, Tucumán, Cuyo y Chile, Prohistoria, Rosario, 2011, pp. 77-91
} 
una autoridad. Así, lo evidencian las posturas discordantes sobre los privilegios en el pueblo de indios de Baradero, quienes litigaron por considerarse propietarios del terreno solicitado en merced en el Rincón de San Pedro, aquellos que estaban en posesión de los terrenos donde se organizaba el nuevo asentamiento de San Fernando, o la apelación del cabildo de Buenos Aires al Consejo de Indias al considerar perjudicial para su jurisdicción las decisiones del virrey sobre nuevos impuestos para solventar la construcción del canal y el establecimiento de la nueva villa de San Fernando.

Las respuestas a las solicitudes de privilegios tuvieron duraciones variables, pero en los casos analizados tardaron años en concretarse o lo hicieron parcialmente. Durante las tramitaciones -y también desde antes de efectuarse- los pedidos estuvieron acompañadas de otras prácticas sociales, económicas y también políticas que fueron materializando cada pueblo. Así, aunque no hubiese llegado el permiso, Merlo fomentó el poblamiento del pueblo; los curas de Santiago del Baradero buscaron limitar las costumbres y el accionar de los caciques del pueblo de indios; los pobladores del Rincón de San Pedro ocuparon de manera continua el terreno antes y después de la solicitud de merced; el virrey Sobremonte acudió a cabildos y corporaciones que no fuesen el cabildo de Buenos Aires para conseguir fuerza de trabajo y plata para la construcción del canal vinculado a San Fernando.

Ante la complejidad de los procesos de formación de los pueblos, y los cuestionamientos que fueron surgiendo, resulta comprensible que hayan sido varios los actores políticos que participaron en cada caso. Cabe señalar que las características sociales, económicas y hasta la situación de autoridad de los sujetos parecieran haber generado una base para actuar o fundamentar servicios, pero no produjeron mecánicamente los resultados por ellos esperados. Los contactos personales-institucionales de Merlo no impidieron los 17 años de espera para el permiso, y la experiencia y autoridad del virrey Sobremonte, o del obispo Malvar y Pintos, encontraron limitaciones en su accionar.

Cada proceso de conformación de un pueblo de españoles abordado tuvo sus propias características y ritmos. En los casos analizados en Buenos Aires, los pueblos tuvieron en común, aunque en diferente orden, el acceso a un determinado terreno asignado para conformar un pueblo de españoles, la formalización a partir de la aprobación del plano correspondiente, el registro de la presencia de población (a partir de un censo o de firmas de los pobladores), una capilla funcionando, y el reconocimiento de una denominación propia para cada asentamiento. Además de la casuística imperante en la relación de la monarquía con sus súbditos, la diversidad de sujetos y la dinámica de los contextos, en los distintos casos se puso en evidencia cierta búsqueda de oportunidad en la manera de actuar, el momento o la estrategia elegida, propias de la acción política. 
Independientemente de los logros alcanzados y los limites encontrados en el proceso de conformación de cada pueblo, diferentes actores compartieron la aspiración de gobierno propio y aumentar o consolidar el alcance de su jurisdicción, ya sea convirtiendo el pueblo de españoles en villa o manteniéndose como pueblo de indios. Sin embargo, las defensas de los propios privilegios y jurisdicciones del cabildo de Buenos Aires y las coyunturas vividas en la región, influyeron, entre otras cuestiones, en el entramado de relaciones de poder de la monarquía, restringiendo el acto de aprobación real necesario para obtener el anhelado privilegio.

Por último, cabe contrastar, en próximos trabajos, aquellas comunidades que lograron constituirse en villas en la región rioplatense con los pueblos de españoles que no lo lograron y que fueron la mayoría en la campaña de Buenos Aires. Sin embargo, insistimos en el objetivo propuesto, que consideramos alcanzado, de no opacar la valoración de los pueblos de españoles como cuerpos políticos de la monarquía hispánica durante el siglo XVIII y continuar indagando en las implicancias de esta característica para periodos posteriores.

Mar del Plata, mayo de 2016 